\title{
Assessment of the Relationship between Hamstring Tightness and Pelvic Tilt in Cerebral Palsy: Are We Overdoing Hamstring Releases in Children with Spastic Bilateral CP, GMFCS Level I-III?
}

\author{
Mohamed Tageldeen Mohamed, MD', Salmeen Awad Salmeen Bahassan, MSc ${ }^{1,2}$, \\ Nader M. Diab, $M D^{1}$ and Ahmed Samir Barakat, $M D^{1}$ \\ ${ }^{1}$ Orthopedic and Trauma Surgery Department, Cairo University, Cairo, Egypt \\ ${ }^{2}$ Orthopedic Specialist, Ministry of Health, Sanaa, Yemen
}

\begin{abstract}
Background: The principle that all diplegic CP patients need hamstring release is controversial as this may further aggravate gait with apparent hamstring tightness.

Methods: In 50 consecutive ambulating purely spastic diplegic children (100 limbs), with a mean age of 6.4 y having bilateral hamstring tightness with a popliteal angle $\geq 50^{\circ}$ the Thomas test was done and the popliteal, modified popliteal angle and the hamstring shift were determined. Radiologically, the sacrofemoral angle (SFA) and the lumbar lordosis angel were measured. The correlations between the SFA and hamstring shift, lumbar lordosis angle and hamstring shift and between the SFA and the lumbar lordosis angle were analyzed and the effect of muscle imbalance on these angles was assessed.

Results: $84.6 \%$ ( 22 children) with a hyperlordotic spine had a positive hamstring shift while all 8 kyphotic patients had a negative hamstring shift. 26 (86.7\%) of the 30 cases with decreased SFA (anterior pelvic tilt) had apparent hamstring tightness (positive hamstring shift), while all 8 cases with increased SFA (posterior tilt) had negative hamstring shift (positive bilateral popliteal test) [1].

Positive correlations were identified between the hamstring shift angle and the Thomas test (Pearson correlation ( $r$ ) $=0.690)$, between the hamstring shift and the lumbar lordosis angle $(r=0.666)$ and SFA $(r=-0.626)$ and an inverse correlation between SFA and lumbar lordosis $(r=-0.820)$.

Conclusion: Evaluating the pelvic tilt through measurement of SFA along with positive hamstring shift, negates the need for lengthening a normal hamstring muscle with an apparent tightness, thus decreasing the potential complications of over-lengthening.
\end{abstract}

\section{Keywords}

$\mathrm{CP}$ cerebral palsy, Hamstring release in hamstring tightness, Apparent and true hamstring tightness in $\mathrm{CP}$, Sacrofemroal angel (SFA), Positive hamstring shift and Thomas test

\section{Introduction}

Hamstring spasticity is one of the main problems in cerebral palsy. It has long been believed that children with crouch gait have hamstring spasticity and this has been the focus of several recent studies. They revealed that hamstring muscles are usually normal in length in most of these children. Even though the length of the hamstring is normal, it appears contracted when anterior pelvic tilt increases. Hamstring release in this condition may further increase the pelvic tilt. Moreover, hip flexion contracture along with weakness of the triceps surae are contributing factors in anterior pelvic tilt and crouch gait, respectively [2].
* Corresponding author: Ahmed Samir Barakat, Orthopedic Surgery and Traumatology Department, Cairo University Hospitals, Kasr Alainy Street, Cairo 11562, Egypt, Ph: +2-(0)11-02-73-2222, Fax: +2-02-628884

Accepted: February 09, 2021

Published online: February 11, 2021

Citation: Mohamed MT, Bahassan SAS, Diab NM, et al. (2021) Assessment of the Relationship between Hamstring Tightness and Pelvic Tilt in Cerebral Palsy: Are We Overdoing Hamstring Releases in Children with Spastic Bilateral CP, GMFCS Level I-III?. J Orthop Surg Tech 3(2):167-174 
Citation: Mohamed MT, Bahassan SAS, Diab NM, et al. (2021) Assessment of the Relationship between Hamstring Tightness and Pelvic Tilt in Cerebral Palsy: Are We Overdoing Hamstring Releases in Children with Spastic Bilateral CP, GMFCS Level I-III?. J Orthop Surg Tech 3(2):167-174

Hip flexion contracture is a common deformity in children and adolescents who have cerebral palsy. If individuals are non-weight bearing, the flexion contractures usually are not of much significance. For independently ambulating children, a hip flexion contracture can increase lordosis and can prevent hip extension in midstance phase and is therefore somewhat restrictive. The ground reaction force passes from anterior to the hip and posterior to the knee due to hip flexor tightness thereby exaggerating crouching [2].

As part of the underlying pathology of $\mathrm{CP}$, soleus weakness is frequently present. Besides, soleus deficiency stemming from Achilles tendon release may lead to diminished retraction of the tibia. Thus, during stance phase the forward tibial advancement is enhanced and the ankle dorsiflexes, leading to loss of the support moment of the soleus to extend the knee and consequently the knee collapses in flexion with secondary hamstring contracture and crouch pattern [2].

The hamstrings are biarticular muscles originating from the ischial tuberosity, so changes in the pelvic sagittal orientation would have significant implications on the apparent hamstring length. Without doubt, kinematic three-dimensional gait analysis provides a plethora of relative accurate data aiding in identification and quantification of the patient specific deficits. However, in many regions in the world gait labs are sparse and data interpretation is subject to a learning curve, therefore alternative methods should be available. Although we intentionally focused in this study on the static assessment of the relationship between pelvic tilt by measuring the sacrofemoral angle and hamstring length on assessing the static hamstring tightness using the bilateral popliteal test, we are fully aware of the pivotal importance of the dynamic examination and gait studies in reaching a conclusive assessment in walking children with crouch gait in spastic dipegia. Integrating our findings with the results of dynamic examination and gait analysis would be the objective of a future study to combine both static and dynamic measures to aid in the assessment process and decision-making.

The hamstrings are not only knee flexors, but they are one of the two major hip extensors as well, and thus assessment of the other hip extensor muscle, the gluteus maximums, is imperative before even considering doing a hamstring release [3].

The balance between the hip extensors and flexors is not the only determinant of pelvic tilt, but the abdominal muscles, especially the rectus femoris, is an important factor in controlling the resting pelvic tilt as it acts as a posterior pelvic rotator. Indeed, in some patients strengthening of the abdominal muscles is all that is needed to relieve the hamstring from the effect of excessive anterior tilt $[4,5]$.

The concept of apparent hamstring tightness and bilateral popliteal angle measurement was introduced to address hamstring release overdoing, as not all cases with knee flexion deformity were found to be due to true hamstring tightness.

The purpose of this study is the evaluation of hamstring contracture to differentiate between true and apparent ham- string tightness caused by an anterior pelvic tilt. This study aims to elucidate the effect of abnormal pelvic tilting on the functional length of the hamstrings, through analysis of clinical and radiological data, and by additionally analyzing muscle imbalance i.e. contracture of hamstrings or iliopsoas or both. Identifying the relationship between the excessive static anterior pelvic tilt and apparent hamstring tightness, alongside the imperative dynamic assessment help cerebral palsy surgeons decide which child would benefit from hamstring release and avoid the side effects in children who are not indicated.

\section{Materials and Methods}

This study was conducted after receiving Ethical Board approval between May 2017 and February 2018 at Abu Elresh Pediatric University Hospital, Cairo University, Egypt to evaluate 50 ambulating children with spastic cerebral palsy having bilateral hamstring tightness with a popliteal angle $\geq$ $50^{\circ}$. All caregivers signed a written consent after having been informed in detail about the study and the above mentioned clinical and radiological examinations.

All consecutive children with diplegic cerebral palsy (100 lower limbs) presenting to our outpatient clinic were evaluated, including 26 females and 24 males with the youngest patient 4.5-years and the eldest 12.5-years-old (mean age 6.4 y). The inclusion criteria were ambulating children with Gross Motor Function Classification System (GMFCS) Level I-III, [6,7] with pure spastic cerebral palsy and bilateral hamstring tightness and a popliteal angle of $\geq 50^{\circ}$. Patients with hemiplegic, dyskinetic and a mixed variety of cerebral palsy, history of soft tissue or bony surgery for gait correction or selective dorsal rhizotomy and pelvic or spinal asymmetry in frontal plain were excluded.

After thorough history taking, careful examination was done for all cases. This included observational gait analysis, GMFCS and concurrent soft tissue contractures of the lower limb.

A full-circle manual universal goniometer was utilized to clinically assess hamstring tightness through the popliteal angle and the modified popliteal angle. Clinical examination including observational gait analysis and clinical sagittal alignment was conducted by the two senior authors consecutively and independently in two different examination rooms. Dedicated study nurses aided in patient positioning and recorded the data in each room determined by the examiner. The average value was calculated at the end of the day for each patient. Clinical sagittal spine alignment was determined by lateral visual inspection in standing position and just categorized into hyperlordotic, normal and kyphotic.

\section{Popliteal and Modified Popliteal Angle for Hamstring Tightness}

The patient was positioned supine and relaxed on an examination table and the hip was flexed to $90^{\circ}$ with the contralateral hip positioned in full extension. No force was used while extending the knee while performing the popliteal and bilateral popliteal test. The ipsilateral flexed knee was then 


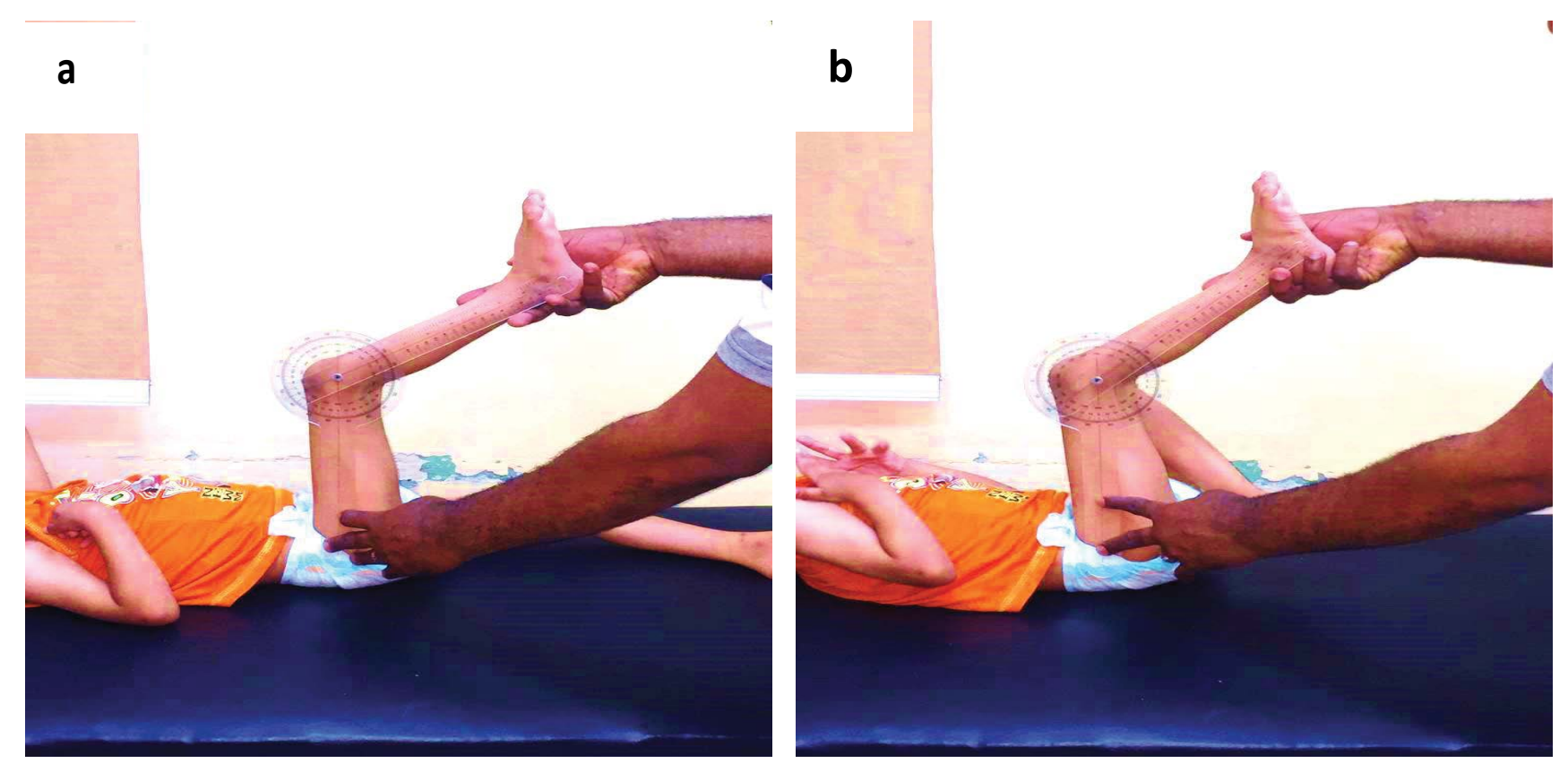

Figure 1: (a) Measurement of popliteal; (b) and modified popliteal angle.

extended, and the angle between the vertical and the position to which the tibia may be extended defined the popliteal angle. Normal popliteal angles vary and are age and gender dependent and range from $0^{\circ}$ to $49^{\circ}$ with a mean value of $26^{\circ}$ in normal children 4 years and older. Boys are usually tighter than girls and both become tighter with increasing age, especially around the time of the adolescent growth spurt. Values greater than $50^{\circ}$ in any giving age are considered abnormal [8]. Both knees were evaluated, if the two limbs were asymmetric the side with the largest angle was recorded.

The modified popliteal angle is measured with the contralateral hip in a flexed position to eliminate the effect of an anterior pelvic tilt. The ipsilateral hip is then flexed to $90^{\circ}$ followed by ipsilateral knee extension. The angle between the retained position and the vertical plane is measured again using the full-circle manual universal goniometer. A significantly smaller popliteal angle with the corrected pelvic position is referred to as a hamstring shift. The value of the popliteal angle with a neutral pelvis is a measure of the true hamstring contracture and the value at which the lordosis unveils is the functional hamstring contracture. The difference between the two represents the degree of hamstring shift. A hamstring shift $>20^{\circ}$ usually indicates excessive anterior pelvic tilt [1] (Figure 1).

\section{Thomas Test for Hip Flexion Contracture}

Thomas test is used to measure the hip flexion contracture. The patient was positioned supine with the limb in question overhanging the distal end of the examining table. The opposite hip was fully flexed to flatten the lordosis of the lumbar spine and the pelvis was locked to prevent pelvic motion. This was achieved by palpating the verticalized line formed between the anterior superior iliac spine (ASIS) and the posterior superior iliac spine (PSIS). Any degree of hip flexion oc- curring during correction of lumbar lordosis was considered as a positive Thomas test [1].

\section{Radiological Assessment for Hip Motion Range through SFA}

The range of hip motion was evaluated using the sacro-femoral angle (SFA). This was obtained via a standardized lateral standing lumbosacral X-ray radiograph with a focus film distance of $115 \mathrm{~cm}$. GMFCS III patients were supported by their caregivers during the examination. The lateral pelvic radiograph was obtained in an erect position including the lower lumbar vertebrae and upper third of the femur. A line was drawn along the superior surface of the sacrum (S1) and another along the femoral shaft. The intersection of these lines defines the SFA, which should normally lie between $45^{\circ}$ and $65^{\circ}$. Its validity has been previously reported by Wei, et al. [9].

The lumbar lordosis angle (LL) was measured from the same X-ray and is derived from the intersection of the perpendicular line of the superior endplate of $L 1$ and the perpendicular line of the superior endplate of S1. The reported angle of lumbar lordosis in normal children and adolescents was reported to be $48.0 \pm 11.7^{\circ}$ [10] (Figure 2).

The correlations between the SFA and hamstring shift, lumbar lordosis angle and hamstring shift and between the SFA and the lumbar lordosis angle were analyzed statistically and the effect of muscle imbalance on these angles was assessed.

Statistical analysis was done with SPSS 23.0 (IBM, Armonk, New York, USA). Quantitative variables were expressed in the form of mean, standard deviation (SD), minimum and maximum and qualitative variables in the form of numbers (No.) and percentages (\%). Data were explored for normality using Kolmogorov-Smirnov test of normality, which showed that 
Citation: Mohamed MT, Bahassan SAS, Diab NM, et al. (2021) Assessment of the Relationship between Hamstring Tightness and Pelvic Tilt in Cerebral Palsy: Are We Overdoing Hamstring Releases in Children with Spastic Bilateral CP, GMFCS Level I-III?. J Orthop Surg Tech 3(2):167-174

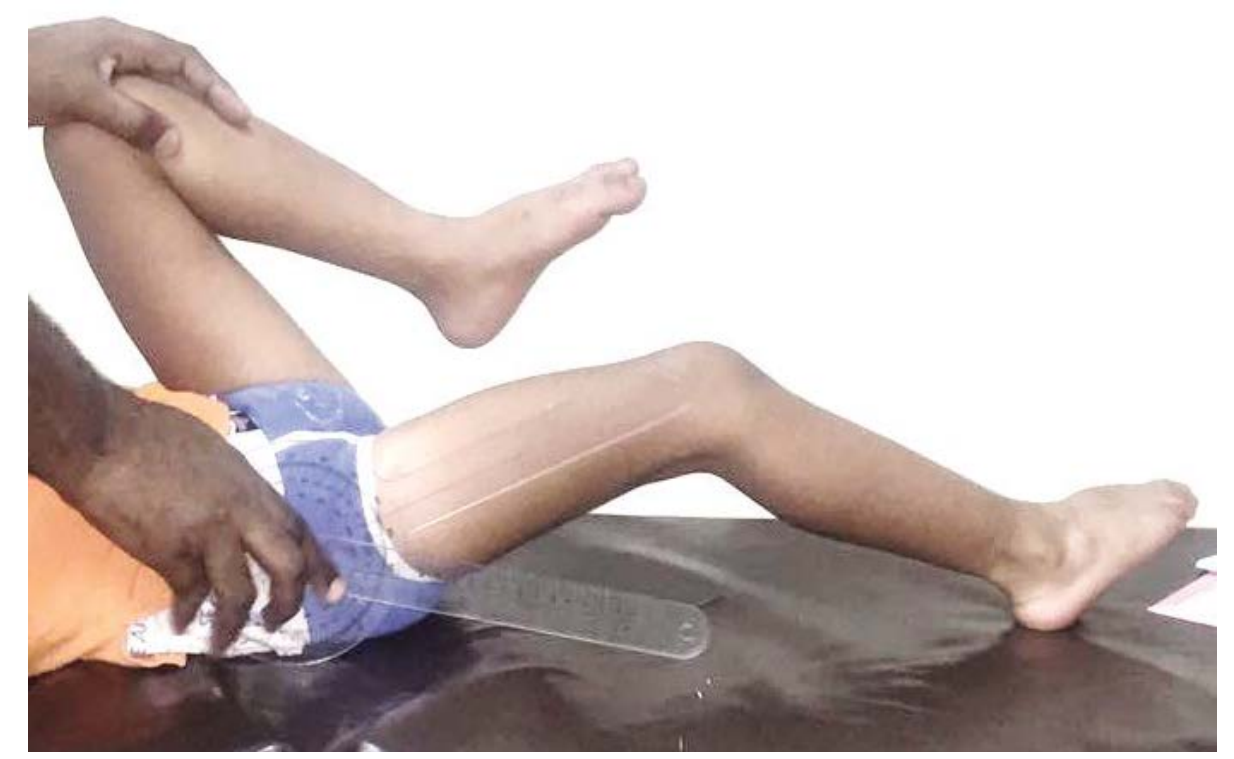

Figure 2: Measurement of hip flexion contracture using Thomas test.

Table 1: Correlation between Thomas test and hamstring shift.

\begin{tabular}{|c|c|c|c|c|c|}
\hline \multicolumn{3}{|l|}{ Variable } & \multicolumn{2}{|l|}{ Hamstring shift } & \multirow{8}{*}{\begin{tabular}{|l} 
P-value \\
$<0.001$
\end{tabular}} \\
\hline & & & Positive $\left(\geq 20^{\circ}\right)($ No. $=26)$ & Negative $\left(<20^{\circ}\right)($ No. $=24)$ & \\
\hline \multirow[t]{6}{*}{ Thomas test } & \multirow{3}{*}{$\begin{array}{l}\text { Positive } \\
\text { (No. = 34) }\end{array}$} & Count & 26 & 8 & \\
\hline & & $\%$ within Thomas test & $26(76.5 \%)$ & $8(23.5 \%)$ & \\
\hline & & $\%$ within Hamstring shift & $26(100.0 \%)$ & $8(33.3 \%)$ & \\
\hline & \multirow{3}{*}{$\begin{array}{l}\text { Negative } \\
(\text { No. = 16) }\end{array}$} & Count & 0 & 16 & \\
\hline & & $\%$ within Thomas test & $0(0.0 \%)$ & $16(100.0 \%)$ & \\
\hline & & $\%$ within Hamstring shift & $0(0.0 \%)$ & $16(66.7 \%)$ & \\
\hline
\end{tabular}

the data was normally distributed. Comparison of categorical variables between two groups was performed using the Chisquare test. The Pearson correlation coefficient ( $r$ ) was used to analyze the degree of association between two variables. The confidence interval was set to $95 \%$ and the $p$ value to 0.05 .

\section{Results}

Fifty children with cerebral palsy with bilateral hamstring tightness were examined. The GMFCs was applied to determine the functional performance of the children. One third, 16 patients (32\%) were GMFCs II, two thirds, 34 patients (68\%) were GMFCs III, whereas no cases were classified as GMFCs I. 17 children (34\%) presented with crouch gait, and $19(38 \%)$ with jumping gait and $6(12 \%)$ with apparent equinus gait, while the remaining 8 children $(16 \%)$ had non-classified gait patterns per the $\mathrm{CP}$ diplegic gait pattern description of Rodda, et al. [11].

Clinical evaluation of the low back showed that 24 cases were hyperlordotic (48\%), whereas only 8 cases $(16 \%)$ had a flat or kyphotic back and the remaining 18 patients (36\%) had a normal sagittal lumbar alignment. Regarding the clinical spine alignment, there was no inter-observer or intra-observer differenceto report. 34 children (68\%) had a positive Thomas test (hip flexor contracture) and only 26 patients (52\%) had positive hamstring shift $\geq 20^{\circ}$.

Radiological assessment of lumbo-pelvic region revealed 26 children (52\%) to be hyperlordotic and only 8 children $(16 \%)$ to have a kyphotic lumbar spine. 30 children (60\%) had a decreased (anterior pelvic tilt) and $8(16 \%)$ had an increased SFA (posterior tilt).

All cases with a positive hamstring shift (26 patients (52\%)) had a positive Thomas test. While 8 cases $(23.5 \%)$ with positive Thomas test (total of 34 patients, 68\%) had a negative hamstring shift. All cases with a negative Thomas test (16 patients) had a negative hamstring shift (Table 1 ).

Among those with a hyperlordotic lumbar spine (26 patients $(52 \%)), 22$ children $(84.6 \%)$ had a positive hamstring shift. All 8 cases with a flat/kyphotic lumbar spine had a negative hamstring shift (true hamstring tightness). 26 (86.7\%) of the 30 cases with decreased SFA (anterior pelvic tilt) had apparent hamstring tightness (positive hamstring shift), while all 8 cases with increased SFA (posterior tilt) had negative hamstring shift (Table 2 and Table 3 ). 
Citation: Mohamed MT, Bahassan SAS, Diab NM, et al. (2021) Assessment of the Relationship between Hamstring Tightness and Pelvic Tilt in Cerebral Palsy: Are We Overdoing Hamstring Releases in Children with Spastic Bilateral CP, GMFCS Level I-III?. J Orthop Surg Tech 3(2):167-174

Table 2: Correlation between lumbo-pelvic parameters and hamstring shift.

\begin{tabular}{|c|c|c|c|c|c|}
\hline \multirow{2}{*}{\multicolumn{3}{|c|}{ Variable }} & \multicolumn{2}{|l|}{ Hamstring shift } & \multirow{2}{*}{ P-value } \\
\hline & & & \multirow{2}{*}{$\begin{array}{l}\text { Positive }\left(\geq 20^{\circ}\right)(\text { No. }=26) \\
22\end{array}$} & \multirow{2}{*}{$\begin{array}{l}\text { Negative }\left(<20^{\circ}\right)(\text { No. }=24) \\
4\end{array}$} & \\
\hline \multirow{9}{*}{$\begin{array}{l}\text { Angle of } \\
\text { lordosis }\end{array}$} & \multirow{3}{*}{$\begin{array}{l}\text { Increased } \\
\text { (Hyperlordotic) } \\
\text { (No. = 26) }\end{array}$} & Count & & & \multirow{9}{*}{$<0.001$} \\
\hline & & $\%$ within Angle of lordosis & $22(84.6 \%)$ & $4(15.4 \%)$ & \\
\hline & & $\%$ within Hamstring shift & $22(84.6 \%)$ & $4(16.7 \%)$ & \\
\hline & \multirow{3}{*}{$\begin{array}{l}\text { Normal } \\
\text { (No. }=16 \text { ) }\end{array}$} & Count & 4 & 12 & \\
\hline & & $\%$ within Angle of lordosis & $4(25.0 \%)$ & $12(75.0 \%)$ & \\
\hline & & $\%$ within Hamstring shift & $4(15.4 \%)$ & $12(50.0 \%)$ & \\
\hline & \multirow{3}{*}{$\begin{array}{l}\text { Decreased (Flat or } \\
\text { Kyphotic) (No. = 8) }\end{array}$} & Count & 0 & 8 & \\
\hline & & $\%$ within Angle of lordosis & $0(0.0 \%)$ & $8(100.0 \%)$ & \\
\hline & & $\%$ within Hamstring shift & $0(0.0 \%)$ & $8(33.3 \%)$ & \\
\hline \multirow{9}{*}{$\begin{array}{l}\text { Sacro femoral } \\
\text { angle }\end{array}$} & \multirow{3}{*}{$\begin{array}{l}\text { Decreased (Anterior } \\
\text { tilt) (No. = 30) }\end{array}$} & Count & 26 & 4 & \multirow{9}{*}{$<0.001$} \\
\hline & & $\%$ within sacrofemoral angle & $26(86.7 \%)$ & $4(13.3 \%)$ & \\
\hline & & $\%$ within Hamstring shift & $26(100.0 \%)$ & $4(16.7 \%)$ & \\
\hline & \multirow{3}{*}{$\begin{array}{l}\text { Normal } \\
\text { (No. = 12) }\end{array}$} & Count & 0 & 12 & \\
\hline & & $\%$ within sacrofemoral angle & $0(0.0 \%)$ & $12(100.0 \%)$ & \\
\hline & & $\%$ within Hamstring shift & $0(0.0 \%)$ & $12(50.0 \%)$ & \\
\hline & \multirow{3}{*}{$\begin{array}{l}\text { Increased (Posterior } \\
\text { tilt) (No. = 8) }\end{array}$} & Count & 0 & 8 & \\
\hline & & $\%$ within sacrofemoral angle & $0(0.0 \%)$ & $8(100.0 \%)$ & \\
\hline & & $\%$ within Hamstring shift & $0(0.0 \%)$ & $8(33.3 \%)$ & \\
\hline
\end{tabular}

Table 3: Correlation between the lumbo-pelvic parameters and Thomas test.

\begin{tabular}{|c|c|c|c|c|c|}
\hline & & & \multicolumn{2}{|l|}{ Thomas test } & \multirow{2}{*}{ P-value } \\
\hline & & & Positive (No. = 34) & Negative (No. = 16) & \\
\hline \multirow{9}{*}{ Angle of lordosis } & \multirow{3}{*}{$\begin{array}{l}\text { Increased (Hyper-lordotic) } \\
\text { (No. = 26) }\end{array}$} & Count & 24 & 2 & \multirow{9}{*}{$<0.001$} \\
\hline & & $\%$ within Angle of lordosis & $24(92.3 \%)$ & $2(7.7 \%)$ & \\
\hline & & $\%$ within Hamstring shift & $24(70.6 \%)$ & $2(12.5 \%)$ & \\
\hline & \multirow{3}{*}{$\begin{array}{l}\text { Normal } \\
\text { (No. = 16) }\end{array}$} & Count & 10 & 6 & \\
\hline & & $\%$ within Angle of lordosis & $10(62.5 \%)$ & $6(37.5 \%)$ & \\
\hline & & $\%$ within Hamstring shift & $10(29.4 \%)$ & $6(37.5 \%)$ & \\
\hline & \multirow{3}{*}{$\begin{array}{l}\text { Decreased (Flat or Kyphotic) } \\
\text { (No. = 8) }\end{array}$} & Count & 0 & 8 & \\
\hline & & $\%$ within Angle of lordosis & $0(0.0 \%)$ & $8(100.0 \%)$ & \\
\hline & & $\%$ within Hamstring shift & $0(0.0 \%)$ & $8(50.0 \%)$ & \\
\hline \multirow{9}{*}{ Sacro-femoral angle } & \multirow{3}{*}{$\begin{array}{l}\text { Decreased (Anterior tilt) } \\
\text { (No. }=\mathbf{3 0})\end{array}$} & Count & 28 & 2 & \multirow{9}{*}{$<0.001$} \\
\hline & & $\%$ within sacrofemoral angle & $28(93.3 \%)$ & $2(6.7 \%)$ & \\
\hline & & $\%$ within Hamstring shift & $28(82.4 \%)$ & $2(12.5 \%)$ & \\
\hline & \multirow{3}{*}{$\begin{array}{l}\text { Normal } \\
\text { (No. = 12) }\end{array}$} & Count & 6 & 6 & \\
\hline & & $\%$ within sacrofemoral angle & $6(50.0 \%)$ & $6(50.0 \%)$ & \\
\hline & & $\%$ within Hamstring shift & $6(17.6 \%)$ & $6(37.5 \%)$ & \\
\hline & \multirow{3}{*}{$\begin{array}{l}\text { Increased (Posterior tilt) } \\
\text { (No. = 8) }\end{array}$} & Count & 0 & 8 & \\
\hline & & $\%$ within sacrofemoral angle & $0(0.0 \%)$ & $8(100.0 \%)$ & \\
\hline & & $\%$ within Hamstring shift & $0(0.0 \%)$ & $8(50.0 \%)$ & \\
\hline
\end{tabular}

There was a highly significant positive correlation between the hamstring shift angle (Table 4) and the Thomas test (Pearson correlation $(r)=0.690)$. Moreover, there were highly significant correlations between the hamstring shift and the angle of lumbar lordosis $(r=0.666)$ and SFA $(r=-0.626)$. There was an inversely significant correlation between SFA and lumbar lordosis $(r=-0.820)$. 
Citation: Mohamed MT, Bahassan SAS, Diab NM, et al. (2021) Assessment of the Relationship between Hamstring Tightness and Pelvic Tilt in Cerebral Palsy: Are We Overdoing Hamstring Releases in Children with Spastic Bilateral CP, GMFCS Level I-III?. J Orthop Surg Tech 3(2):167-174

Table 4: Correlation between clinical and radiological parameters of lumbo-pelvic-hip complex.

\begin{tabular}{|c|c|c|c|c|}
\hline & \multicolumn{2}{|l|}{ Hamstring shift angle } & \multicolumn{2}{|l|}{ Thomas test } \\
\hline & Pearson Correlation ( $r$ ) & P. value & Pearson Correlation ( $r$ ) & P. value \\
\hline Popliteal angle & 0.320 & 0.024 & 0.104 & 0.473 \\
\hline Contralateral popliteal angle & -0.778 & 0.001 & -0.617 & 0.01 \\
\hline Hamstring shift angle & 1 & & 0.690 & 0.01 \\
\hline Thomas test angle & 0.690 & 0.01 & 1 & \\
\hline Angle of lordosis & 0.666 & 0.01 & 0.741 & 0.01 \\
\hline \multirow[t]{3}{*}{ Sacrofemoral angle } & -0.626 & 0.01 & -0.627 & 0.01 \\
\hline & \multicolumn{2}{|l|}{ Angle of lumbar lordosis } & \multicolumn{2}{|l|}{ Sacrofemoral angle } \\
\hline & Pearson Correlation (r) & P. value & Pearson Correlation (r) & P. value \\
\hline Popliteal angle & -0.462 & 0.04 & -0.284 & 0.04 \\
\hline Contralateral popliteal angle & -0.625 & 0.01 & 0.426 & 0.02 \\
\hline Hamstring shift in angle & 0.666 & 0.01 & -0.626 & 0.01 \\
\hline Thomas test angle & 0.741 & 0.01 & -0.627 & 0.01 \\
\hline Angle of lordosis & 1 & & -0.820 & 0.01 \\
\hline Sacrofemoral angle & -0.820 & 0.01 & 1 & \\
\hline
\end{tabular}

\section{Discussion}

The need for hamstring lengthening in most $\mathrm{CP}$ cases remains controversial. Although, most surgeon believe that non-surgical treatment for hamstring contracture offers little chance to improve function, hamstring over-lengthening will weaken the muscle and exaggerate crouching [12,13].

Excessive anterior pelvic tilt, which is commonly seen in diplegic and quadriplegic $\mathrm{CP}$, will produce a hamstring shift in conjunction with apparent flexed knee gait [14].

This work assessed the need for hamstring release in $\mathrm{CP}$ patients with a popliteal angle more than $50^{\circ}$. Although the statistical data suggest a significant correlation between anterior pelvic tilt and a positive bilateral hamstring test, it is a static relationship, however, dynamic examination and gait studies must be considered, especially in walking GMFCS spastic CP types before concluding the need for hamstring release. This study revealed that most cases of knee flexion deformity (popliteal angle $>50^{\circ}$ ) had apparent hamstring tightness.

This was confirmed clinically through a positive Thomas test in $68 \%$ of cases, radiologically through a decreased SFA in $52 \%$ of cases and a hyperlordotic lumbar spine in $60 \%$ of cases.

In this study, three distinct groups were observed:

- The first group presented by hamstring tightness with a popliteal angle of $\geq 50^{\circ}$, negative hamstring shift and negative Thomas test. The pelvis may be level, or the pelvis and lumbar spine are extended by virtue of the hamstring muscles. That is the typical presentation of true hamstring tightness (16 children).

- The second group presented by hamstring tightness (popliteal angle of $\geq 50^{\circ}$ ), negative hamstring shift and positive Thomas test. The effect of hamstring muscles will coun- teract that of the iliopsoas, so the pelvis may be level and the lumbar spine is normal. This scenario represents a true hamstring and iliopsoas tightness ( 8 children).

- The third group showed tight hamstring muscle (popliteal angle of $\geq 50^{\circ}$ ), positive hamstring shift $\left(\geq 20^{\circ}\right)$ and positive Thomas test. Here the iliopsoas (hip flexor) has the primary and dominant effect on the pelvis, so the pelvis is flexed, and the lumbar spine is hyperlordotic. The hamstring is overstretched and elongated. This situation signifies apparent hamstring tightness (26 children).

A hamstring shift of $\geq 20^{\circ}$ is usually indicative of excessive anterior pelvic tilt either from tight hip flexors or weak hip extensor or weak abdominals [14].

The statistically significant association between the variables in each group demonstrate the relationship between the pelvic tilt and the functional length of the hamstrings, therefore correct judgement of the true length cannot be done accurately enough to determine the need for lengthening, without objectively assessing the pelvic tilt, especially in a patient with hip flexion deformity, lumbar lordosis and with positive hamstring shift.

Delp, et al. identified only 3 out of 14 children (21\%) with crouch gait that had hamstrings that were shorter than normal by 1 SD. Most cases with crouch gait had hamstrings of normal length or longer than normal [14]. In comparison, 17 children (34\%) of our study presented with crouch gait and only $6(12 \%)$ of them had true hamstring tightness.

Joshi $Y$, et al. stated in 2018 that $33.3 \%$ of CP patients had an average pelvic tilt $<5^{\circ}$ denoting an anterior pelvic tilt, $44.4 \%$ had normal pelvic tilt which was between $5-10^{\circ}$ and $22.2 \%$ of the patients had a pelvic tilt of more than $10^{\circ}$ indicating a posterior pelvic tilt. In the this study, the measurement of pelvic tilt was done with the more reliable SFA and the results were $60 \%$ of children had an anterior pelvic tilt, 
Citation: Mohamed MT, Bahassan SAS, Diab NM, et al. (2021) Assessment of the Relationship between Hamstring Tightness and Pelvic Tilt in Cerebral Palsy: Are We Overdoing Hamstring Releases in Children with Spastic Bilateral CP, GMFCS Level I-III?. J Orthop Surg Tech 3(2):167-174

$34 \%$ had normal pelvic tilt and only $16 \%$ had posterior pelvic tilt [15]. These differences between the aforementioned and this study may be explained by the use of more accurate and objective methods of measuring the pelvic tilt by describing the relationship between pelvis and femur through the SFA.

Glard, et al. reported a statistically significant correlation between the lumbar curve and the hip flexion contracture. High values of lumbar lordotic angle were correlated with high values of hip flexion contracture [16]. In this study, the correlation between hip flexor contracture and radiological parameters of the lumbopelvic region revealed that $92.3 \%$ of cases with a hyperlordotic lumbar spine had a hip flexor contracture, while no cases with a kyphotic lumbar spine had a hip flexor contracture. There is a significant negative correlation $(r=-0.626, P=0.001)$ between Thomas test and pelvic tilt which was measured by the SFA.

McCarthy, et al. found a significant correlation between the sitting lumbar curve and popliteal angle $(r=-0.77, P<$ 0.01). With increase of the popliteal angle, the amount of lumbar lordosis decreased. This correlation was less significant when the patient was standing ( $r=-0.59)$ [17]. In this study the correlation between popliteal angle and lumbar lordosis is also statistically significant with $(r=-0.462$ and $P$ $=0.004$ ) with our measurements obtained in a standing position. Long, et al. revealed the positive impact of percutaneous hamstring lengthening and serial extension casting on the functional outcome of 19 CP patients with crouch gait. 15 patients $(80 \%)$ responded significantly or moderately to the procedure [18].

Obeid and his colleagues proved that lumbar lordosis correlated moderately with knee flexion contracture $(r=0.42)$ while pelvic tilt correlated moderately with knee flexion angle $(r=0.55)$. Furthermore, lack of lumbar lordosis correlated best with knee flexion angle $(r=0.72)$ [19]. Analogous results were obtained in this study evidenced by the correlation between knee flexion contraction (popliteal angle) and lumbar lordosis ( $r=0.462, P=0.04)$, and between knee flexion and SFA $(r=0.28, P=0.01)$, and between lumbar lordosis and SFA $(-0.820)$.

Harada T, et al. (1993) found that the mean average of SFA in CP patients was diminished, because of the flexion contractures of their hips, while their average lumbar lordosis was greater than normal because of the increased lordosis. The decreased SFA may be an expression of the spasticity in the hip flexors whereas the spasticity of the lumbar muscles contributes to the increased lumbar lordosis. The angle of lumbar lordosis increased with decrease in the SFA $(r=0.442)$ which was verified by similar results found by this study $(r=-0.820)$ [20].

The SFA obviates the falsifying effect of the pelvic and lumbar spine during flexion of the hip and can be readily obtained via lateral $\mathrm{X}$-rays. It is consistent and provides reliable and objective data regarding the lumbo-pelvic complex [9].

There are many variables that synergize to determine the degree of stretch and apparent and true length of the hamstrings, therefore isolating these variables and studying the relationship between these variables is the key to compre- hend this complex interacting mechanism. Yet, the above described assessment method is simple, readily feasible even in remote areas and provides reproducible results which may guide the pediatric orthopedic health provider to the appropriate management.

Nonetheless, to become widely adopted, the findings of this study need to be confirmed on a larger scale by multicentric randomized control studies involving surgical or non-surgical treatment modalities based on the interpretation of the data.

\section{Conclusion}

Evaluating the pelvic tilt through measurement of SFA along with positive hamstring shift, negates the need for lengthening a normal hamstring muscle with an apparent tightness, thus decreasing the potential complications of over-lengthening. This assessment is simple, readily available and provides reproducible results.

\section{Authors Declarations}

The authors declare that this work was not funded publicly or privately, whatsoever.

The authors declare that they there are no conflicts of interests regarding this work.

This work was conducted in full compliance to the Declaration of Helsinki and its amendments.

\section{References}

1. Novacheck TF, Trost JP, Sohrweide S (2010) Examination of the child with cerebral palsy. Orthop Clin North Am 41: 469-488.

2. Bilgili F, Temelli Y, Akalan NE (2012) Assessment of the hip and knee flexion contractures in cerebral palsy patients with crouch gait. J Acad Res Med 2: 10-14.

3. Shamsoddini A, Amirsalari S, Hollisaz MT, et al. (2014) Management of spasticity in children with cerebral palsy. Iran J Pediatr 24: $345-351$.

4. Vaz G, Roussouly P, Berthonnaud E, et al. (2002) Sagittal morphology and equilibrium of pelvis and spine. Eur Spine J 11: 8087.

5. Hodges PW, Richardson CA (1997) Contraction of the abdominal muscles associated with movement of the lower limb. Phys Ther 77: 132-144.

6. Palisano R, Rosenbaum P, Walter S, et al. (1997) Development and reliability of a system to classify gross motor function in children with cerebral palsy. Dev Med Child Neurol 39: 214-223.

7. Paulson A, Vargus-Adams J (2017) Overview of four functional classification systems commonly used in cerebral palsy. Children 4: 30.

8. Katz K, Rosenthal A, Yosipovitch Z (1992) Normal ranges of popliteal angle in children. J Pediatr Orthop 12: 229-231.

9. Wei XZ, Xu XM, Wang F, et al. (2015) Radiological assessment of the sacrofemoral angle: A novel method to measure the range of hip joint flexion. Chin Med J (Engl) 128: 2318-2321.

10. Mac Thiong JM, Labelle H, Berthonnaud E, et al. (2007) Sagittal spinopelvic balance in normal children and adolescents. Eur Spine J 16: 227-234. 
Citation: Mohamed MT, Bahassan SAS, Diab NM, et al. (2021) Assessment of the Relationship between Hamstring Tightness and Pelvic Tilt in Cerebral Palsy: Are We Overdoing Hamstring Releases in Children with Spastic Bilateral CP, GMFCS Level I-III?. J Orthop Surg Tech 3(2):167-174

11. Rodda JM, Graham HK, Carson L, Galea MP, Wolfe R (2004) Sagittal gait patterns in spastic diplegia. J Bone Jt Surg Ser B 86: 251258.

12. Matjacic Z, Olensek A (2007) Biomechanical characterization and clinical implications of artificially induced crouch walking: Differences between pure iliopsoas, pure hamstrings and combination of iliopsoas and hamstrings contractures. J Biomech 40: 491-501.

13. Rhie TY, Sung KH, Park MS, et al. (2013) Hamstring and psoas length of crouch gait in cerebral palsy: A comparison with induced crouch gait in age- and sex-matched controls. J Neuroeng Rehabil 10: 10.

14. Delp SL, Arnold AS, Speers RA, et al. (1996) Hamstrings and psoas lengths during normal and crouch gait: Implications for muscle-tendon surgery. J Orthop Res 14: 144-151.

15. Joshi, Y, Bass A. P V. (2018) Hamstring shift test: Is it a measure of contributory knee flexion deformity? Orthop Proceedings- Eur Fed Natl Assoc Orthop Traumatol.
16. Glard Y, Launay F, Viehweger E, et al. (2005) Hip flexion contracture and lumbar spine lordosis in myelomeningocele. J Pediatr Orthop 25: 476-478.

17. McCarthy JJ, Betz RR (2000) The relationship between tight hamstrings and lumbar hypolordosis in children with cerebral palsy. Spine (Phila Pa 1976) 25: 211-213.

18. Long JT, Cobb L, Garcia MC, et al. (2019) Improved clinical and functional outcomes in crouch gait following minimally invasive hamstring lengthening and serial casting in children with cerebral palsy. J Pediatr Orthop.

19. Obeid I, Hauger O, Aunoble S, et al. (2011) Global analysis of sagittal spinal alignment in major deformities: Correlation between lack of lumbar lordosis and flexion of the knee. Eur Spine J 20: 681-685.

20. Harada T, Ebara S, Anwar MM, et al. (1993) The lumbar spine in spastic diplegia. A radiographic study. J Bone Jt Surg Ser B 75: 534-537. 